Check for updates

Cite this: RSC Adv., 2019, 9, 23545

Received 12th June 2019

Accepted 22nd July 2019

DOI: $10.1039 / c 9 r a 04412 d$

rsc.li/rsc-advances

\section{Visible-light photocatalytic performance, recovery and degradation mechanism of ternary magnetic $\mathrm{Fe}_{3} \mathrm{O}_{4} / \mathrm{BiOBr} / \mathrm{BiOl}$ composite $\uparrow$}

\author{
Jianhui Li, Fan Yang, Quan Zhou, Lijie Wu, Wenying Li, Ruipeng Ren* \\ and Yongkang LV $\mathbb{D}^{*}$ *
}

The ternary magnetic $\mathrm{Fe}_{3} \mathrm{O}_{4} / \mathrm{BiOBr} / \mathrm{BiOI}(x: 3: 1)$ photocatalysts were successfully synthesized by a facile solvothermal method. The samples were characterized by XRD, SEM, EDS, ICP-AES, XPS, UV-vis DRS, PL and VSM. Nitrogen-containing dye RhB was used as a degradation substrate to evaluate the photocatalytic degradation activities of the samples. The photocatalytic performance of $\mathrm{Fe}_{3} \mathrm{O}_{4} / \mathrm{BiOBr} / \mathrm{BiOl}(0.4: 3: 1)$ is superior to other $\mathrm{Fe}_{3} \mathrm{O}_{4} / \mathrm{BiOBr} / \mathrm{BiOl}\left(x: 3: 1\right.$ ). Compared with binary magnetic $\mathrm{Fe}_{3} \mathrm{O}_{4} / \mathrm{BiOBr}(0.5: 1)$ prepared in our previous work, the $\mathrm{Fe}_{3} \mathrm{O}_{4} / \mathrm{BiOBr} / \mathrm{BiOl}(0.4: 3: 1)$ has obvious advantages in photocatalytic activity and adsorption capacity. And the specific surface area $\left(48.30 \mathrm{~m}^{2} \mathrm{~g}^{-1}\right)$ is much larger than that of the previous report $\left(\mathrm{Fe}_{3} \mathrm{O}_{4} / \mathrm{BiOBr} / \mathrm{BiOl}(0.5: 2: 2)\right)$ synthesized by a co-precipitation method. Besides, after $25 \mathrm{~s}$ of magnetic field, $\mathrm{Fe}_{3} \mathrm{O}_{4} / \mathrm{BiOBr} / \mathrm{BiOl}(0.4: 3: 1)$ can be rapidly separated from water. After eight recycling cycles, the magnetic properties, photocatalytic activity, crystallization and morphology of the $\mathrm{Fe}_{3} \mathrm{O}_{4} / \mathrm{BiOBr} / \mathrm{BiOl}$ $(0.4: 3: 1)$ catalyst remain good. The possible photocatalytic degradation mechanism of $\mathrm{RhB}$ under $\mathrm{Fe}_{3} \mathrm{O}_{4} /$ $\mathrm{BiOBr} / \mathrm{BiOl}(0.4: 3: 1)$ photocatalyst was also proposed. The results indicate that the ternary magnetic $\mathrm{Fe}_{3} \mathrm{O}_{4} /$ $\mathrm{BiOBr} / \mathrm{BiOl}(0.4: 3: 1)$ composite with high photocatalytic degradation efficiency, good magnetic separation performance and excellent recyclability and stability has potential application prospect in wastewater.

\section{Introduction}

The organic pollutants seriously affect the water environment and threaten human health. In particular, synthetic nitrogencontaining dyes (Rhodamine B (RhB), Methyl orange (MO), Congo red, etc) are one of the largest organic pollutants. Many treatment methods have been developed, such as biological methods, membrane separation technology, electrochemical methods, ozone oxidation and so on. $\cdot^{1-3}$ Among them, photocatalytic technology is considered to be a promising and effective environmental pollutant treatment method with high mineralization efficiency, no secondary pollution, energy savings and simple processes. ${ }^{4,5}$ In the past few years, many active photocatalysts have been widely studied, and some of them have been successfully industrialized. ${ }^{6}$ However, the photocatalytic activities of most semiconductor photocatalysts $\left(\mathrm{TiO}_{2}, \mathrm{ZnO}, \mathrm{CdS}, \mathrm{ZnS}, \text { etc. }\right)^{7}$ are low, and their practical applications are greatly restricted by some defects, such as poor utilization rate of visible light, low separation rate of photogenerated electron-hole pairs, and difficult separation from the

Key Laboratory of Coal Science and Technology, Ministry of Education and Shanxi Province, Taiyuan University of Technology, No. 79 Yingze West Street, Taiyuan 030024, China. E-mail: renruipeng888@126.com; yongkanglv@163.com

$\dagger$ Electronic supplementary information (ESI) available. See DOI: 10.1039/c9ra04412d water body, etc. ${ }^{8-10}$ Accordingly, it is necessary to exploit new highly efficient and easily separated visible-light-responsive photocatalysts for degrading organics in water treatment.

In order to alleviate these problems, many attempts have been developed, such as the synthesis of various structures, doping of metal elements, construction of heterojunctions. ${ }^{11,12}$ The construction of heterojunction photocatalysts has been regarded as an efficient way to solve the above-mentioned defects of single semiconductors. The previously reported heterojunction photocatalysts include $\mathrm{BiVO}_{4} / \mathrm{TiO}_{2},{ }^{13} \mathrm{BiOI} / \mathrm{BiOBr},{ }^{14}$ $\mathrm{ZnS} / \mathrm{CdS},{ }^{15} \mathrm{BiVO}_{4} / \mathrm{Bi}_{2} \mathrm{Ti}_{2} \mathrm{O}_{7}{ }^{16}$ etc. Although this way improves the photocatalytic activities of the photocatalysts, the separation of the photocatalysts remains difficult.

Due to low-cost, high electrical conductivity $\left(2 \times 10^{4} \mathrm{~S} \mathrm{~m}^{-1}\right)$, excellent magnetic properties $\left(58.0 \mathrm{emu} \mathrm{g}^{-1}\right)$, high theoretical capacity $\left(924 \mathrm{~mA} \mathrm{~h} \mathrm{~g}{ }^{-1}\right.$ ), and eco-friendly properties, $\mathrm{Fe}_{3} \mathrm{O}_{4}$ becomes one of the most promising used magnetic materials in $\mathrm{Fe}_{3} \mathrm{O}_{4}, \gamma-\mathrm{Fe}_{2} \mathrm{O}_{3}$ and $\mathrm{MFe}_{2} \mathrm{O}_{4}{ }^{17}$ Based on the above advantages, $\mathrm{Fe}_{3} \mathrm{O}_{4}$ can act as an electron transporter to inhibit recombination of photogenerated electron-hole pairs. In addition, $\mathrm{Fe}_{3} \mathrm{O}_{4}$ particles have been modified with photocatalysts to improve adsorption capacity and enlarge the specific surface area of the photocatalysts. ${ }^{18-20}$ The detailed reasons for choosing $\mathrm{Fe}_{3} \mathrm{O}_{4}$ to combine with photocatalysts are: (1) enhancement of specific surface area can increase the active site of the catalyst; (2) excellent magnetic character facilitates the recycling of the 
photocatalysts; (3) the existence of $\mathrm{Fe}-\mathrm{OH}$ can improve the adsorptive capacity of the photocatalysts. ${ }^{20}$ Many heterojunction photocatalysts combined with $\mathrm{Fe}_{3} \mathrm{O}_{4}$ particles such as $\mathrm{Fe}_{3} \mathrm{O}_{4} / \mathrm{AgBr} / \mathrm{ZnO},{ }^{21} \quad \mathrm{BiVO}_{4} / \mathrm{Bi}_{2} \mathrm{Ti}_{2} \mathrm{O}_{7} / \mathrm{Fe}_{3} \mathrm{O}_{4},{ }^{20} \quad \mathrm{~g}-\mathrm{C}_{3} \mathrm{~N}_{4} / \mathrm{Fe}_{3} \mathrm{O}_{4} /$ $\mathrm{MnWO}_{4},{ }^{22} \mathrm{Ag}_{3} \mathrm{PO}_{4} / \mathrm{ZnO} / \mathrm{Fe}_{3} \mathrm{O}_{4},{ }^{23}$ etc. have been prepared to enhance the recycling ability. To the best of our knowledge, limited research has been reported about ternary magnetic $\mathrm{Fe}_{3} \mathrm{O}_{4} / \mathrm{BiOBr} / \mathrm{BiOI}$ photocatalysts treating organic wastewater under visible light. Gao et al. ${ }^{24}$ have prepared $\mathrm{Fe}_{3} \mathrm{O}_{4} / \mathrm{BiOBr} / \mathrm{BiOI}$ $(0.5: 2: 2)$ composite by precipitation method to solve the problem that the $\mathrm{BiOBr} / \mathrm{BiOI}(2: 2)$ heterojunction photocatalyst is difficult to be separated from aqueous phase. However, $\mathrm{Fe}_{3} \mathrm{O}_{4} / \mathrm{BiOBr} / \mathrm{BiOI}(0.5: 2: 2)$ composite synthesized by precipitation has the defects of non-uniform particle size and small specific surface area. Because the products prepared by solvothermal approach own high crystallinity, uniform particle size distribution and high yield, solvothermal approach has attracted more and more attention.

In this study, the ternary magnetic $\mathrm{Fe}_{3} \mathrm{O}_{4} / \mathrm{BiOBr} / \mathrm{BiOI}$ $(x: 3: 1) \quad(x=0.2,0.3,0.4$ and 0.5$)$ photocatalysts were successfully synthesized by a facile solvothermal method. The samples are characterized by X-ray diffraction (XRD), scanning electron microscope (SEM), X-ray photoelectron spectroscopy (XPS), Brunauer-Emmett-Teller (BET), UV-vis diffuse reflection spectroscopy (UV-vis DRS) and photoluminescence analysis (PL). Magnetic properties of magnetic samples were detected by vibrating sample magnetometer (VSM). The photocatalytic activities of the samples were evaluated by degrading RhB. The ternary magnetic $\mathrm{Fe}_{3} \mathrm{O}_{4} / \mathrm{BiOBr} / \mathrm{BiOI}(0.4: 3: 1)$ photocatalyst was used in recycling experiments, and the crystallization, morphology and magnetic properties before and after recycling were detected by XRD, SEM and VSM. Besides, $\mathrm{Fe}_{3} \mathrm{O}_{4} / \mathrm{BiOBr} /$ BiOI $(0.4: 3: 1)$ photocatalyst was compared the photocatalytic performance, adsorption capacity and magnetic property with those of previous studies. In the end, the mechanism of photocatalytic degradation of $\mathrm{RhB}$ under $\mathrm{Fe}_{3} \mathrm{O}_{4} / \mathrm{BiOBr} / \mathrm{BiOI}$ $(0.4: 3: 1)$ photocatalyst was analyzed in detail.

\section{Experimental}

\section{Materials and synthesis of the photocatalysts}

Materials. Ferric(III) chloride hexahydrate $\left(\mathrm{FeCl}_{3} \cdot 6 \mathrm{H}_{2} \mathrm{O}\right)$ and Rhodamine B (RhB) were obtained from Aladdin. Sodium acetate $\left(\mathrm{NaHCO}_{3}\right)$, potassium bromide $(\mathrm{KBr})$, potassium iodide (KI), ethanol, ethylene glycol (EG) were gotten from Kermel Chemical Reagent, Tianjin. Bismuth nitrate $\left(\mathrm{Bi}\left(\mathrm{NO}_{3}\right)_{3} \cdot 5 \mathrm{H}_{2} \mathrm{O}\right)$ was purchased from Macklin. All the chemical reagents were used as received without any further purification.

Synthesis of $\mathrm{Fe}_{3} \mathrm{O}_{4}$ nanoparticles. The $\mathrm{Fe}_{3} \mathrm{O}_{4}$ particles were prepared by a facile solvothermal method. $1 \mathrm{~g}(0.005 \mathrm{~mol})$ $\mathrm{FeCl}_{3} \cdot 6 \mathrm{H}_{2} \mathrm{O}$ were dissolved in $80 \mathrm{ml}$ of EG. $3.6 \mathrm{~g} \mathrm{NaHCO}_{3}$ was added in the stirring process. Then, the mixed solution was heated to $50{ }^{\circ} \mathrm{C}$, and stirred evenly, then transferred to $100 \mathrm{ml}$ Teflon-lined autoclave at $180{ }^{\circ} \mathrm{C}$ for $12 \mathrm{~h}$. The black solid deposit was washed for three times with ethanol and water, respectively, and separated by magnetic field. The black particles were dried in vacuum at $70{ }^{\circ} \mathrm{C}$ for $12 \mathrm{~h}$.
Preparation of $\mathrm{Fe}_{3} \mathrm{O}_{4} / \mathrm{BiOBr} / \mathrm{BiOI}$ composites. The $\mathrm{BiOBr}$, BiOI, BiOBr/BiOI $(3: 1)$ and $\mathrm{Fe}_{3} \mathrm{O}_{4} / \mathrm{BiOBr} / \mathrm{BiOI}(x: 3: 1)$ composites ( $x$ represents the mole ratio of $\mathrm{Fe}_{3} \mathrm{O}_{4}$ ) were also synthesized by solvothermal method according to the published paper. ${ }^{25}$ In $\mathrm{Fe}_{3} \mathrm{O}_{4} / \mathrm{BiOBr} / \mathrm{BiOI}(x: 3: 1)$ composites, the mole ratios of $\mathrm{Fe}_{3} \mathrm{O}_{4}$ were chosen as $0.2,0.3,0.4$ and 0.5. BiOBr/BIOI (3:1) and $\mathrm{Fe}_{3} \mathrm{O}_{4} / \mathrm{BiOBr} / \mathrm{BiOI}(x: 3: 1)$ composites with different mole ratios of $\mathrm{Fe}_{3} \mathrm{O}_{4}$ is abbreviated as $\mathrm{Br} / \mathrm{I}(3: 1), \mathrm{F} / \mathrm{Br} / \mathrm{I}$ $(0.2: 3: 1), \mathrm{F} / \mathrm{Br} / \mathrm{I} \quad(0.3: 3: 1), \mathrm{F} / \mathrm{Br} / \mathrm{I} \quad(0.4: 3: 1)$ and $\mathrm{F} / \mathrm{Br} / \mathrm{I}$ $(0.5: 3: 1)$, respectively. The specific dosages of the chemical reagents are shown in Table 1.

\section{Characterization of the samples}

The phase purity and crystal structure of the prepared products were characterized by X-ray diffraction (XRD) analysis. The morphology and microstructures of the particles were investigated by scanning electron microscope (SEM, JSM-7100F), equipped with energy-dispersive X-ray spectroscopy (EDS) to probe elemental analysis. Inductively couple plasma atomic emission spectroscopy (ICP-AES, Varian 720) was used to detect the contents of $\mathrm{Fe}$ and $\mathrm{Bi}$ elements in $\mathrm{Fe}_{3} \mathrm{O}_{4} / \mathrm{BiOBr} / \mathrm{BiOI}$ (0.4: $3: 1)$. X-ray photoelectron spectroscopy (XPS) was used to analyze the chemical valence and composition of the ternary magnetic $\mathrm{Fe}_{3} \mathrm{O}_{4} / \mathrm{BiOBr} / \mathrm{BiOI}(0.4: 3: 1)$ composite. The surface area and textural properties were determined by $\mathrm{N}_{2}$ adsorptiondesorption isotherms on a Quantachrome instrument (ASIQC 050200-6, USA). The absorption wavelengths of the samples were detected by UV-vis diffuse reflection spectroscopy (UV-vis DRS) on a Hitachi U-4100, Japan. The fate of photogenerated carriers were investigated by photoluminescence analysis (PL) on Elmer fluorescence spectrophotometer. The magnetic properties of magnetic materials were measured by a vibrating sample magnetometer (VSM, LDJ9600).

\section{Photocatalytic activity measurement}

The photocatalytic activities of the samples were evaluated by degrading RhB under visible light irradiation. A $500 \mathrm{~W}$ Xe lamp with a cutoff filter $(\lambda>400 \mathrm{~nm})$ was used as light source. The distance between the liquid surface and the light source is $15 \mathrm{~cm} .0 .035 \mathrm{~g}$ of the prepared catalysts were added to $100 \mathrm{~mL}$ RhB solution ( $20 \mathrm{mg} \mathrm{L}^{-1}$ ). The mixture was mechanically stirred in the dark for 60 minutes to reach absorption-desorption equilibrium between catalyst particles and RhB molecules. The light was then directed at the dispersion at room temperature. About $5 \mathrm{~mL}$ dispersion was token and centrifugally separated out catalyst powder. A 52 UV-vis spectrophotometer (Spectrum instruments, Shanghai) was used to analyze the concentrations of RhB. In the recycling experiment, the $\mathrm{Fe}_{3} \mathrm{O}_{4} / \mathrm{BiOBr} / \mathrm{BiOI}$ $(0.4: 3: 1)$ was separated from the dispersion with a magnet and washed with ethanol and ultrapure water several times sequentially.

\section{Detection of final products}

RhB molecule contains nitrogen atoms, so the final products $\left(\mathrm{NH}_{4}{ }^{+}, \mathrm{NO}_{2}{ }^{-}\right.$or $\left.\mathrm{NO}_{3}{ }^{-}\right)$of nitrogen atoms can be used to measure 
Table 1 The specific dosages of the chemical reagents

\begin{tabular}{|c|c|c|c|c|}
\hline Samples & $\mathrm{Fe}_{3} \mathrm{O}_{4}(\mathrm{mmol})$ & $\begin{array}{l}\mathrm{Bi}\left(\mathrm{NO}_{3}\right)_{3} \cdot 5 \mathrm{H}_{2} \mathrm{O} \\
(\mathrm{mmol})\end{array}$ & $\mathrm{KBr}(\mathrm{mmol})$ & $\mathrm{KI}(\mathrm{mmol})$ \\
\hline $\mathrm{BiOBr}$ & - & 16 & 16 & - \\
\hline $\mathrm{BiOI}$ & - & 16 & - & 16 \\
\hline $\mathrm{Br} / \mathrm{I}^{a}(3: 1)$ & - & 16 & 12 & 4 \\
\hline $\mathrm{F} / \mathrm{Br} / \mathrm{I}^{b}(0.2: 3: 1)$ & 0.8 & 16 & 12 & 4 \\
\hline $\mathrm{F} / \mathrm{Br} / \mathrm{I}(0.3: 3: 1)$ & 1.2 & 16 & 12 & 4 \\
\hline $\mathrm{F} / \mathrm{Br} / \mathrm{I}(0.4: 3: 1)$ & 1.6 & 16 & 12 & 4 \\
\hline $\mathrm{F} / \mathrm{Br} / \mathrm{I}(0.5: 3: 1)$ & 2.0 & 16 & 12 & 4 \\
\hline
\end{tabular}

the degradation of RhB. Ammonia nitrogen $\left(\mathrm{NH}_{4}{ }^{+}-\mathrm{N}\right)$, nitrate nitrogen $\left(\mathrm{NO}_{3}{ }^{-}-\mathrm{N}\right)$ or nitrite nitrogen $\left(\mathrm{NO}_{2}{ }^{-}-\mathrm{N}\right)$ can be detected by SP-752 visible spectrophotometer (Spectrum instruments, Shanghai). Ammonia nitrogen $\left(\mathrm{NH}_{4}{ }^{+}-\mathrm{N}\right)$ was detected by Nessler's Reagent Spectrometry at $420 \mathrm{~nm}$. Salicylic acidconcentrated sulfuric acid Spectrophotometry was utilized to determine the concentration of nitrate nitrogen $\left(\mathrm{NO}_{3}{ }^{-}-\mathrm{N}\right)$ at $410 \mathrm{~nm}$. $N$-(1-Naphthyl)-ethylenediamine Spectrophotometry was used to analyze nitrite nitrogen $\left(\mathrm{NO}_{2}{ }^{-}-\mathrm{N}\right)$ at $540 \mathrm{~nm}$.

\section{Results and discussion}

\section{Characterization results}

Crystal structure. Fig. 1 shows the XRD patterns of $\mathrm{BiOBr}$, BiOI, $\mathrm{Fe}_{3} \mathrm{O}_{4}$ and $\mathrm{Fe}_{3} \mathrm{O}_{4} / \mathrm{BiOBr} / \mathrm{BiOI}(x: 3: 1)$ with different $\mathrm{Fe}_{3} \mathrm{O}_{4}$ $(x)$ mole ratios. The strong and sharp diffraction peaks implicate that all prepared products are highly crystalline. The all characteristic peaks of the prepared pure $\mathrm{BiOBr}$ and $\mathrm{BiOI}$ are well indexed to the tetragonal phase BiOBr (JCPDS no. 73-2061) and BiOI (JCPDS no. 10-0445), respectively. Meanwhile, all diffraction peaks of the prepared $\mathrm{Fe}_{3} \mathrm{O}_{4}$ can be clearly

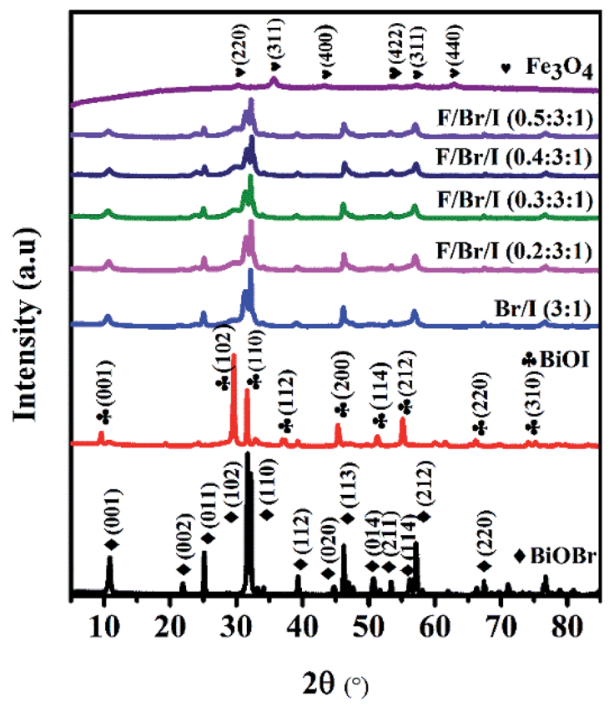

Fig. 1 XRD patterns of $\mathrm{BiOBr}, \mathrm{BiOl}, \mathrm{Fe}_{3} \mathrm{O}_{4}$ and $\mathrm{Fe}_{3} \mathrm{O}_{4} / \mathrm{BiOBr} / \mathrm{BiOI}$ $(x: 3: 1)(x=0.2,0.3,0.4$ and 0.5$)$ with different $\mathrm{Fe}_{3} \mathrm{O}_{4}(x)$ molar ratios (Br/l : $\mathrm{BiOBr} / \mathrm{BiOl} ; \mathrm{F} / \mathrm{Br} / \mathrm{l}: \mathrm{Fe}_{3} \mathrm{O}_{4} / \mathrm{BiOBr} / \mathrm{BiOl}$ ). corresponded to JCPDS card no. 19-0629. As for the BiOBr/BiOI (3:1) and $\mathrm{Fe}_{3} \mathrm{O}_{4} / \mathrm{BiOBr} / \mathrm{BiOI}(x: 3: 1)$ composites, all peaks are well indexed to tetragonal phase $\mathrm{BiOBr}$, BiOI and the crystal $\mathrm{Fe}_{3} \mathrm{O}_{4}$, and no characteristic diffraction peaks of other impurities are observed. The results indicate that the prepared binary $\mathrm{BiOBr} / \mathrm{BiOI}(3: 1)$ and ternary magnetic $\mathrm{Fe}_{3} \mathrm{O}_{4} / \mathrm{BiOBr} / \mathrm{BiOI}$ $(x: 3: 1) \quad(x=0.2,0.3,0.4$ and 0.5$)$ composites are only composed of $\mathrm{BiOBr}, \mathrm{BiOI}$ and $\mathrm{Fe}_{3} \mathrm{O}_{4}$ phases. In addition, the intensity of diffraction peaks of $\mathrm{BiOBr}$ and $\mathrm{BiOI}$ weaken gradually with the increase of $\mathrm{Fe}_{3} \mathrm{O}_{4}$ mole ratios in ternary magnetic $\mathrm{Fe}_{3} \mathrm{O}_{4} / \mathrm{BiOBr} / \mathrm{BiOI}(x: 3: 1)(x=0.2,0.3,0.4$ and 0.5$)$ composites, implying that $\mathrm{Fe}_{3} \mathrm{O}_{4}$ particles have been successfully deposited on the surface of $\mathrm{BiOBr} / \mathrm{BiOI}(3: 1)$ composite. ${ }^{26}$

Morphology and composition characterization. As shown in Fig. 2a-c, the prepared pure $\mathrm{Fe}_{3} \mathrm{O}_{4}, \mathrm{BiOBr}$ and $\mathrm{BiOI}$ exhibit uniform nanospheres of about 600-700 nm, regular nanosheets of about 100-250 nm and irregular nanosheet structures, respectively. Compounded $\mathrm{BiOBr}$ and $\mathrm{BiOI}$ with the mole ratio of $3: 1$, the binary $\mathrm{BiOBr} / \mathrm{BiOI}(3: 1)$ composite shows a uniform flower-like hierarchical microsphere structure with average diameter of about $1600 \mathrm{~nm}$. As for $\mathrm{Fe}_{3} \mathrm{O}_{4} / \mathrm{BiOBr} / \mathrm{BiOI}$ $(x: 3: 1)(x=0.2,0.3,0.4$ and 0.5$)$ composites, the flower-like

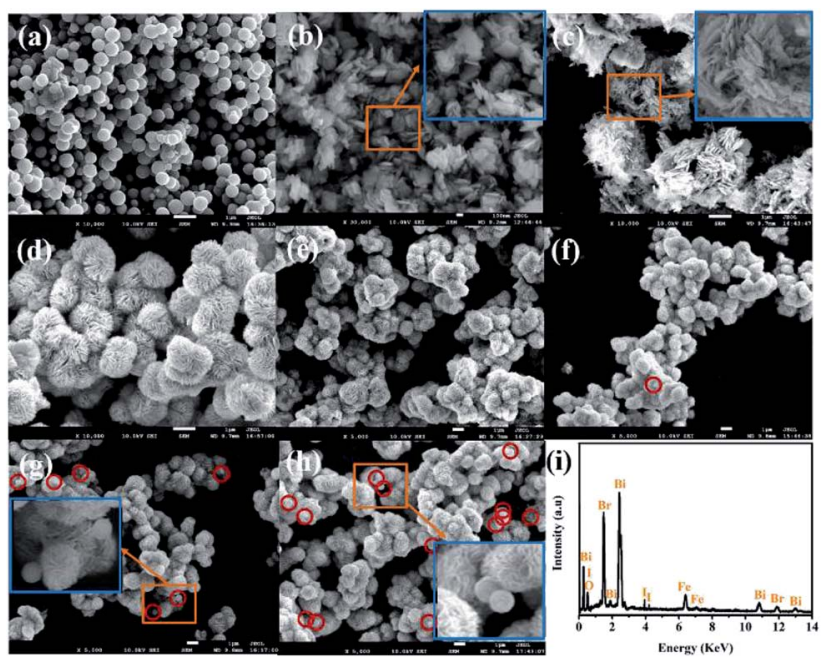

Fig. 2 SEM image of (a) $\mathrm{Fe}_{3} \mathrm{O}_{4}$, (b) $\mathrm{BiOBr}$, (c) $\mathrm{BiOl}$, (d) $\mathrm{BiOBr} / \mathrm{BiOl}(3: 1)$, (e) $\mathrm{Fe}_{3} \mathrm{O}_{4} / \mathrm{BiOBr} / \mathrm{BiOl}(0.2: 3: 1)$, (f) $\mathrm{F} / \mathrm{Br} / \mathrm{l}(0.3: 3: 1)$, (g) $\mathrm{F} / \mathrm{Br} / \mathrm{l}$ $(0.4: 3: 1)$ and (h) $\mathrm{F} / \mathrm{Br} / \mathrm{l}(0.5: 3: 1)$; (i) EDS spectrum of $\mathrm{F} / \mathrm{Br} / \mathrm{I}$ $(0.4: 3: 1)\left(\mathrm{Br} / \mathrm{l}: \mathrm{BiOBr} / \mathrm{BiOl}(3: 1) ; \mathrm{F} / \mathrm{Br} / \mathrm{l}: \mathrm{Fe}_{3} \mathrm{O}_{4} / \mathrm{BiOBr} / \mathrm{BiOl}\right)$. 
hierarchical microsphere structure (Fig. 2e-h) has not changed along with the adding of different mole ratios of $\mathrm{Fe}_{3} \mathrm{O}_{4}$. As seen from the enlarged image of Fig. $2 \mathrm{~g}$ and h, with the increase of mole ratios of $\mathrm{Fe}_{3} \mathrm{O}_{4}$, it is obvious that $\mathrm{Fe}_{3} \mathrm{O}_{4}$ particles adhere to the surface of the binary $\mathrm{BiOBr} / \mathrm{BiOI}(3: 1)$ composite, which is consistent with the result of XRD analysis.

The chemical composition of the ternary magnetic $\mathrm{Fe}_{3} \mathrm{O}_{4} /$ $\mathrm{BiOBr} / \mathrm{BiOI}(0.4: 3: 1)$ composite was carried out by SEM-EDS elemental mapping when the SEM in scanning mode was operated. The EDS spectrum (Fig. 2i and S1 $\dagger$ ) shows strong signals of $\mathrm{Bi}, \mathrm{O}, \mathrm{Br}, \mathrm{I}$ and $\mathrm{Fe}$ elements without detecting any other elements, which demonstrates that the ternary magnetic $\mathrm{Fe}_{3} \mathrm{O}_{4} / \mathrm{BiOBr} / \mathrm{BiOI}(0.4: 3: 1)$ composite is composed of $\mathrm{Bi}, \mathrm{O}$, $\mathrm{Br}$, I and Fe elements. What is more, the quantitative result presents the atomic of $\mathrm{Bi}: \mathrm{O}: \mathrm{Br}: \mathrm{I}: \mathrm{Fe}$ in the ternary magnetic $\mathrm{Fe}_{3} \mathrm{O}_{4} / \mathrm{BiOBr} / \mathrm{BiOI}(0.4: 3: 1)$ composite is $19: 33: 15: 48: 57$, which is in line with theoretical chemometrics ratio of $20: 28: 15: 5: 6$ for $\mathrm{Bi}: \mathrm{O}: \mathrm{Br}: \mathrm{I}: \mathrm{Fe}$ in $\mathrm{Fe}_{3} \mathrm{O}_{4} / \mathrm{BiOBr} / \mathrm{BiOI}$ $(0.4: 3: 1)$ in view of instrumental error, implying that the mole ratio of $\mathrm{Fe}_{3} \mathrm{O}_{4}, \mathrm{BiOBr}$ and $\mathrm{BiOI}$ in the ternary magnetic $\mathrm{Fe}_{3} \mathrm{O}_{4} / \mathrm{BiOBr} / \mathrm{BiOI}(0.4: 3: 1)$ composite is $0.4: 3: 1$.

ICP-AES analysis (Table S1 $\dagger$ ) shows that the mass content (the mass of elements in catalyst per kilogram) of $\mathrm{Fe}$ and $\mathrm{Bi}$ are 671821.2 and $49761.7 \mathrm{mg} \mathrm{kg}^{-1}$ in $\mathrm{Fe}_{3} \mathrm{O}_{4} / \mathrm{BiOBr} / \mathrm{BiOI}(0.4: 3: 1)$ composite, respectively. The molar ratio of the two is calculated to be $2.77: 10$, which is basically consistent with stoichiometric ratio of $3: 10$.

XPS analysis. The typical XPS survey spectrum (Fig. 3a) shows $\mathrm{Bi}, \mathrm{O}, \mathrm{Br}$, I, Fe and $\mathrm{C}$ elements are detected, proving once again that the ternary magnetic $\mathrm{Fe}_{3} \mathrm{O}_{4} / \mathrm{BiOBr} / \mathrm{BiOI}$ $(0.4: 3: 1)$ composite is composed of $\mathrm{Bi}, \mathrm{O}, \mathrm{Br}, \mathrm{I}$ and $\mathrm{Fe}$ five elements. While $\mathrm{C} 1 \mathrm{~s}$ at $284.6 \mathrm{eV}$ as the reference for the binding energies of other elements is the adventitious carbon. As seen in Fig. 3b, two peaks with binding energies at 68.8 and $69.2 \mathrm{eV}$ are $\mathrm{Br} 3 \mathrm{~d}_{5 / 2}$ and $\mathrm{Br} 3 \mathrm{~d}_{3 / 2}$ peaks, respectively. ${ }^{27}$ From the spectra shown in Fig. $3 \mathrm{c}$, the peaks for Bi $4 \mathrm{f}$ are observed, and contain $\mathrm{Bi} 4 \mathrm{f}_{7 / 2}(\mathrm{Bi}(\mathrm{III}))$ and $\mathrm{Bi} 4 \mathrm{f}_{5 / 2}(\mathrm{Bi}(\mathrm{v}))$ peaks. ${ }^{24}$ As for the $\mathrm{O} 1 \mathrm{~s}$, two different oxygen species are presented, the strong peak located at $530.2 \mathrm{eV}$ corresponds to lattice oxygen in $\mathrm{Fe}_{3} \mathrm{O}_{4} / \mathrm{BiOBr} / \mathrm{BiOI}(0.4: 3: 1)$, and the binding energy situated at $531.5 \mathrm{eV}$ is attributed to the hydroxyl groups attached to the surface of the magnetic
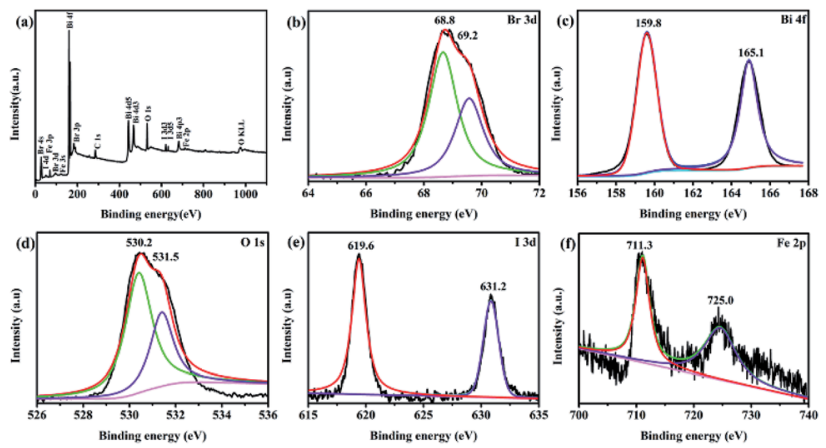

Fig. 3 XPS spectra of $\mathrm{Fe}_{3} \mathrm{O}_{4} / \mathrm{BiOBr} / \mathrm{BiOl}(0.4: 3: 1)$ sample: (a) survey of the photocatalyst; (b) Br 3d; (c) Bi 4f; (d) O 1s; (e) Fe 2p; (f) I 3d. catalyst. ${ }^{28}$ It can be seen from Fig. 3e, the I $3 \mathrm{~d}$ shows two strong peaks at binding energies of 619.6 and $631.2 \mathrm{eV}$, which are matched with $I 3 d_{5 / 2}$ and $I 3 d_{3 / 2}$, respectively. The result confirms the -1 valence of $I$ in the ternary magnetic composite. In addition, the Fe $2 \mathrm{p}$ binding energies of 711.3 and $725.0 \mathrm{eV}$ are attributed to $\mathrm{Fe} 2 \mathrm{p}_{3 / 2}$ and $\mathrm{Fe} 2 \mathrm{p}_{1 / 2}$, confirming the existence of $\mathrm{Fe}^{3+}$ and $\mathrm{Fe}^{2+}$ in the sample. Through the XPS analysis, $\mathrm{Fe}_{3} \mathrm{O}_{4}, \mathrm{BiOBr}$ and $\mathrm{BiOI}$ coexist in the ternary magnetic $\mathrm{Fe}_{3} \mathrm{O}_{4} / \mathrm{BiOBr} / \mathrm{BiOI}(0.4: 3: 1)$ composite, which corresponds to the results of XRD and SEM analysis.

BET surface area analysis. The results of surface area and textural properties are shown in Fig. 4 and Table 2. As shown in Fig. 4, the isotherms of all as-prepared samples correspond to typical IV-type curves with a distinct $\mathrm{H} 3$ hysteresis loop (IUPAC classification), ${ }^{29}$ indicating the presence of $2-50 \mathrm{~nm}$ mesopores. The result of average pore diameters (Table 2) confirms this statement. The pure BiOBr and BiOI display relatively small specific surface area of 14.41 and $14.03 \mathrm{~m}^{2} \mathrm{~g}^{-1}$, and relatively large average pore diameters of 52.76 and $51.61 \mathrm{~nm}$. In addition, the specific surface area of $\mathrm{Fe}_{3} \mathrm{O}_{4}$ is largest with $96.91 \mathrm{~m}^{2} \mathrm{~g}^{-1}$, while the pore volume and average pore diameter are relatively small. After compounded $\mathrm{BiOBr}$ with $\mathrm{BiOI}$, the specific surface area of the formed $\mathrm{BiOBr} / \mathrm{BiOI}$ ( $3: 1$ ) increases significantly to $44.21 \mathrm{~m}^{2} \mathrm{~g}^{-1}$, and the average pore diameter decreases obviously to $21.90 \mathrm{~nm}$. And when $\mathrm{Fe}_{3} \mathrm{O}_{4}$ and $\mathrm{BiOBr} / \mathrm{BiOI}(3: 1)$ are compounded to form ternary magnetic $\mathrm{Fe}_{3} \mathrm{O}_{4} /$ $\mathrm{BiOBr} / \mathrm{BiOI}(x: 3: 1)$ composite, and the specific surface area of $\mathrm{Fe}_{3} \mathrm{O}_{4} / \mathrm{BiOBr} / \mathrm{BiOI}(x: 3: 1)$ increases with the increase of the mole ratios of $\mathrm{Fe}_{3} \mathrm{O}_{4}$, and the pore volume and pore diameter decrease accordingly.

UV-vis DRS analysis. The absorption wavelengths of the photocatalysts can be used to measure the absorptivity to light. The UV-vis diffuse reflectance spectra of $\mathrm{BiOBr}, \mathrm{BiOI}$ and $\mathrm{Fe}_{3} \mathrm{O}_{4} /$ BiOBr/BiOI $(x: 3: 1)$ with different $\mathrm{Fe}_{3} \mathrm{O}_{4}(x)$ mole ratios are shown in Fig. 5. The absorption wavelengths of all samples are in Fig. 5. The absorption wavelengths of all samples are in the

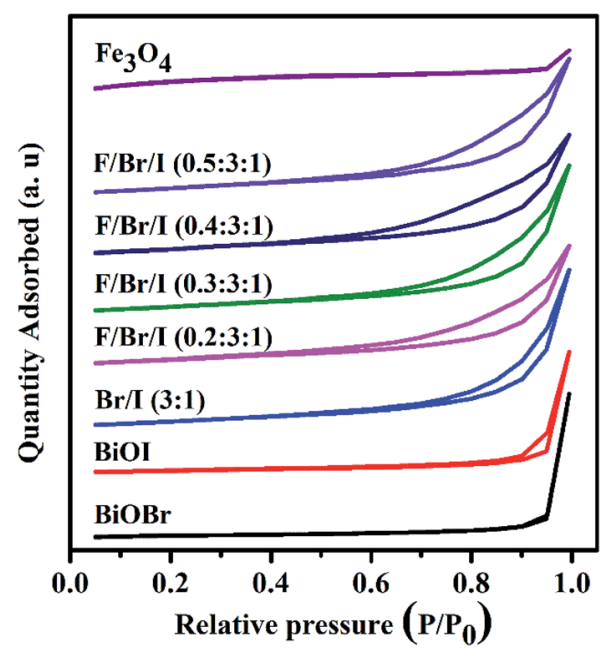

Fig. $4 \mathrm{~N}_{2}$ adsorption-desorption tests of $\mathrm{BiOBr}, \mathrm{BiOl}, \mathrm{Fe}_{3} \mathrm{O}_{4}$ and $\mathrm{Fe}_{3} \mathrm{O}_{4} / \mathrm{BiOBr} / \mathrm{BiOl}(x: 3: 1)(x=0.2,0.3,0.4$ and 0.5$)$ with different $\mathrm{Fe}_{3} \mathrm{O}_{4}(x)$ molar ratios (Br/l : $\mathrm{BiOBr} / \mathrm{BiOl}(3: 1) ; \mathrm{F} / \mathrm{Br} / \mathrm{l}: \mathrm{Fe}_{3} \mathrm{O}_{4} / \mathrm{BiOBr} /$ $\mathrm{BiOl})$. 
Table 2 Characteristics of the prepared samples by $\mathrm{N}_{2}$ adsorptiondesorption tests

\begin{tabular}{llll}
\hline Samples & $S\left(\mathrm{~m}^{2} \mathrm{~g}^{-1}\right)$ & $P\left(\mathrm{~cm}^{3} \mathrm{~g}^{-1}\right)$ & $A(\mathrm{~nm})$ \\
\hline $\mathrm{BiOBr}$ & 14.41 & 0.2152 & 52.76 \\
$\mathrm{BiOI}$ & 14.03 & 0.1810 & 51.61 \\
$\mathrm{Br} / \mathrm{I}^{a}(3: 1)$ & 44.21 & 0.2421 & 21.90 \\
$\mathrm{~F} / \mathrm{Br} / \mathrm{I}^{b}(0.2: 3: 1)$ & 44.82 & 0.2251 & 17.29 \\
$\mathrm{~F} / \mathrm{Br} / \mathrm{I}(0.3: 3: 1)$ & 46.67 & 0.2184 & 19.58 \\
$\mathrm{~F} / \mathrm{Br} / \mathrm{I}(0.4: 3: 1)$ & 48.30 & 0.2193 & 16.18 \\
$\mathrm{~F} / \mathrm{Br} / \mathrm{I}(0.5: 3: 1)$ & 52.59 & 0.1825 & 16.16 \\
$\mathrm{Fe}_{3} \mathrm{O}_{4}$ & 96.91 & 0.0888 & 18.32
\end{tabular}

${ }^{a} \mathrm{BiOBr} / \mathrm{BiOI} .{ }^{b} \mathrm{Fe}_{3} \mathrm{O}_{4} / \mathrm{BiOBr} / \mathrm{BiOI} ; S$ : specific surface area; $P$ : pore volume; $A$ : average pore diameter.

visible region. The band edge of $\mathrm{BiOBr} / \mathrm{BiOI}(3: 1)$ lies between the pure $\mathrm{BiOBr}(425 \mathrm{~nm})$ and $\mathrm{BiOI}(670 \mathrm{~nm})$. In comparison with $\mathrm{BiOBr} / \mathrm{BiOI}(3: 1)$ composite, the absorption wavelengths of the ternary magnetic $\mathrm{Fe}_{3} \mathrm{O}_{4} / \mathrm{BiOBr} / \mathrm{BiOI}(x: 3: 1)$ exhibit slightly red shift, indicating that the introduction of $\mathrm{Fe}_{3} \mathrm{O}_{4}$ can enhance the absorptivity of the photocatalysts to visible light.

PL analysis. The PL analysis results are shown in Fig. 6. The intensity of the diffraction peak can be applied to estimate the recombination probability of photogenerated electron-hole pairs. The stronger the peak is, the greater the recombination probability is. Based on this principle, it can be seen from Fig. 6, the emission peak of the pure $\mathrm{BiOBr}$ is the strongest, indicating that the photogenerated electron-hole pairs, recombination rate is the largest, and that of $\mathrm{BiOBr} / \mathrm{BiOI}(3: 1)$ is second, between $\mathrm{BiOBr}$ and BiOI. ${ }^{30,31}$ While the emission peak of the pure $\mathrm{Fe}_{3} \mathrm{O}_{4}$ is the weakest, predicting the smallest recombination rate of photogenerated electron-hole pairs. The result illustrates that $\mathrm{Fe}_{3} \mathrm{O}_{4}$ owns strong electronic transmission capacity. ${ }^{32}$ As can be seen from Fig. 6, the peak strength of BiOI is second only to that of $\mathrm{Fe}_{3} \mathrm{O}_{4}$. Loaded $\mathrm{Fe}_{3} \mathrm{O}_{4}$ on $\mathrm{BiOBr} / \mathrm{BiOI}$ $(3: 1)$ composite, the photogenerated electron-hole pairs, recombination rate of $\mathrm{Fe}_{3} \mathrm{O}_{4} / \mathrm{BiOBr} / \mathrm{BiOI}(x: 3: 1)$ decreases significantly, which indirectly indicates that the utilization rate of photogenerated carriers is improved.

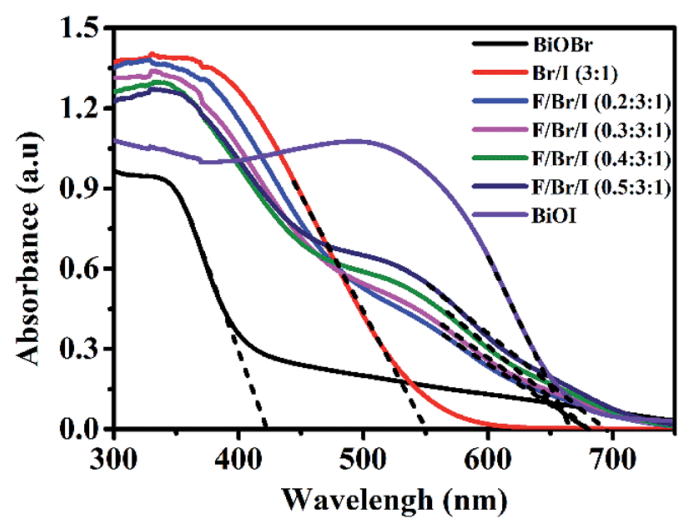

Fig. 5 UV-vis diffuse reflectance spectra of $\mathrm{BiOBr}, \mathrm{BiOl}$ and $\mathrm{Fe}_{3} \mathrm{O}_{4} /$ $\mathrm{BiOBr} / \mathrm{BiOl}(x: 3: 1)(x=0.2,0.3,0.4$ and 0.5$)$ with different $\mathrm{Fe}_{3} \mathrm{O}_{4}(x)$ molar ratios. (Br/l : $\mathrm{BiOBr} / \mathrm{BiOl}$ (3 : 1); $\mathrm{F} / \mathrm{Br} / \mathrm{l}: \mathrm{Fe}_{3} \mathrm{O}_{4} / \mathrm{BiOBr} / \mathrm{BiOl}$ ).

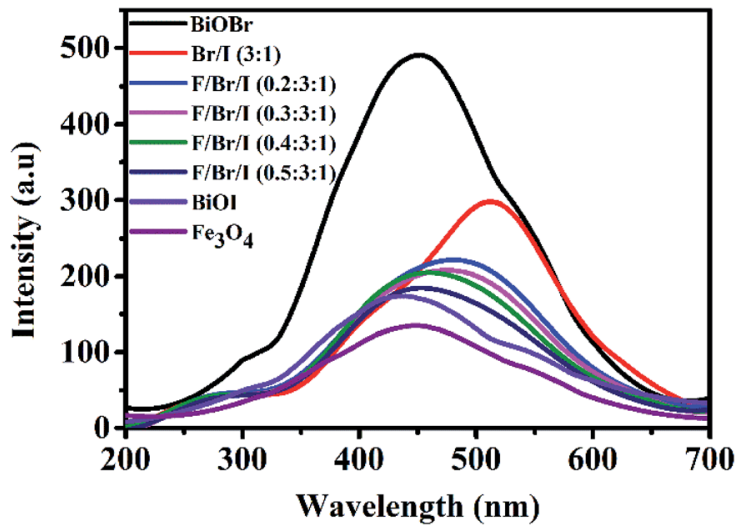

Fig. 6 Photoluminescence (PL) spectra of $\mathrm{BiOBr}, \mathrm{BiOl}, \mathrm{Fe}_{3} \mathrm{O}_{4}$ and $\mathrm{Fe}_{3} \mathrm{O}_{4} / \mathrm{BiOBr} / \mathrm{BiOl}(x: 3: 1)(x=0.2,0.3,0.4$ and 0.5$)$ with different $\mathrm{Fe}_{3} \mathrm{O}_{4}(x)$ molar ratios. (Br/l : $\mathrm{BiOBr} / \mathrm{BiOI}(3: 1) ; \mathrm{F} / \mathrm{Br} / \mathrm{l}: \mathrm{Fe}_{3} \mathrm{O}_{4} / \mathrm{BiOBr} /$ $\mathrm{BiOI}$.

Magnetic analysis. The magnetic properties of the magnetic samples $\left(\mathrm{Fe}_{3} \mathrm{O}_{4}\right.$, and $\mathrm{Fe}_{3} \mathrm{O}_{4} / \mathrm{BiOBr} / \mathrm{BiOI}(x: 3: 1)$ with different $\mathrm{Fe}_{3} \mathrm{O}_{4}(x)$ mole ratios) are shown in Fig. 7. All magnetic samples present good ferromagnetic behavior. ${ }^{33}$ It can be clearly realized that the magnetism of $\mathrm{Fe}_{3} \mathrm{O}_{4} / \mathrm{BiOBr} / \mathrm{BiOI}(x: 3: 1)(x=0.2,0.3$, 0.4 and 0.5$)$ increases with the increase of $\mathrm{Fe}_{3} \mathrm{O}_{4}$ mole ratio (Fig. 7a (inset)). The saturation magnetization (MS) of pure $\mathrm{Fe}_{3} \mathrm{O}_{4}$ and $\mathrm{Fe}_{3} \mathrm{O}_{4} / \mathrm{BiOBr} / \mathrm{BiOI}(x: 3: 1)$ composite $(x=0.2,0.3$, 0.4 and 0.5 ) are 58.28, 2.64, 3.89, 5.10 and $6.27 \mathrm{emu} \mathrm{g}^{-1}$, respectively. Seen from Fig. $7 \mathrm{~b}$, the color of the pure $\mathrm{BiOBr}$ and $\mathrm{BiOI}$ are greyish-white and red-brown, and $\mathrm{BiOBr}$ and $\mathrm{BiOI}$ compound with a mole ratio of $3: 1$ to form bright yellow catalyst. The color of $\mathrm{Fe}_{3} \mathrm{O}_{4}$ is black, when $\mathrm{Fe}_{3} \mathrm{O}_{4}$ combines with $\mathrm{BiOBr} / \mathrm{BiOI}(3: 1)$, the color of the ternary magnetic $\mathrm{Fe}_{3} \mathrm{O}_{4}$ / BiOBr/BiOI $(x: 3: 1)$ composites gradually shift from light brown to reddish brown. The Fig. $7 \mathrm{~b}$ also shows the separation ability of magnetic samples under an external magnetic field. Powder samples dispersed in water present turbidity. After $25 \mathrm{~s}$ of applied magnetic field, the turbid suspensions become clear to varying degrees. The suspensions of the ternary magnetic $\mathrm{Fe}_{3} \mathrm{O}_{4} / \mathrm{BiOBr} / \mathrm{BiOI}(0.2: 3: 1)$ and $\mathrm{Fe}_{3} \mathrm{O}_{4} / \mathrm{BiOBr} / \mathrm{BiOI}(0.3: 3: 1)$ stay a little cloudy, and those of $\mathrm{Fe}_{3} \mathrm{O}_{4} / \mathrm{BiOBr} / \mathrm{BiOI}(0.4: 3: 1)$, $\mathrm{Fe}_{3} \mathrm{O}_{4} / \mathrm{BiOBr} / \mathrm{BiOI}(0.5: 3: 1)$ and $\mathrm{Fe}_{3} \mathrm{O}_{4}$ become very clear. This phenomenon illustrates that when the mole ratio of $\mathrm{Fe}_{3} \mathrm{O}_{4}$ is greater than 0.3 , the synthesized ternary magnetic $\mathrm{Fe}_{3} \mathrm{O}_{4} / \mathrm{BiOBr} /$ BiOI $(x: 3: 1)$ composites have good separation ability in the aqueous solution under an external magnetic field.

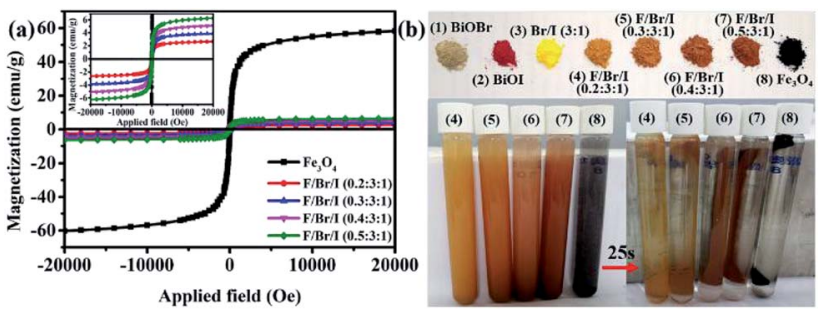

Fig. 7 (a) VSM curves of the magnetic samples; (b) pictures of the samples and magnetic separation performance of the magnetic samples (Br/l : $\mathrm{BiOBr} / \mathrm{BiOl}(3: 1) ; \mathrm{F} / \mathrm{Br} / \mathrm{l}: \mathrm{Fe}_{3} \mathrm{O}_{4} / \mathrm{BiOBr} / \mathrm{BiOl}$ ). 


\section{Photocatalytic performance}

Photocatalytic degradability. Fig. 8a presents the photodegradation of RhB with illumination time over different photocatalysts under visible light. And the kinetic curves transform and first-order kinetic constants $(K)$ of RhB degradation are shown in Fig. 8b and c. When the adsorption-desorption equilibrium reaches, the adsorption capacity of $\mathrm{RhB}$ by the samples can be calculated using $q_{\mathrm{e}}\left(\mathrm{mg} \mathrm{g}^{-1}\right)$.

$$
q_{\mathrm{e}}=\left(C_{0}-C\right) \mathrm{V} / \mathrm{m}
$$

where $C_{0}$ and $C$ are the initial and equilibrium concentrations of RhB in the RhB solution (ppm), $V$ is the solution volume (L), and $m$ is the mass of the catalysts $(\mathrm{g})$. The adsorption capacity of $\mathrm{RhB}$ by the as-prepared samples within $60 \mathrm{~min}$ is presented in the Table 3 . The adsorption rates of $\mathrm{BiOBr}$ and $\mathrm{BiOI}$ to $\mathrm{RhB}$ are 1.5 and $18.1 \%$, and the corresponding adsorption capacities of them are 1.86 and $12.79 \mathrm{mg} \mathrm{g}^{-1}$. Compared to the pure $\mathrm{BiOBr}$ and $\mathrm{BiOI}$, the adsorption capacity of $\mathrm{BiOBr} / \mathrm{BiOI}(3: 1)$ increases greatly to $35.42 \mathrm{mg} \mathrm{g}^{-1}$. It is obvious that the adsorption capacities of $\mathrm{Fe}_{3} \mathrm{O}_{4} / \mathrm{BiOBr} / \mathrm{BiOI}(x: 3: 1)(x=0.2,0.3,0.4$ and $0.5)$ is stronger than that of $\mathrm{BiOBr} / \mathrm{BiOI}(3: 1)$, and increases with the increase of $\mathrm{Fe}_{3} \mathrm{O}_{4}$ when the mole ratio of $\mathrm{Fe}_{3} \mathrm{O}_{4}$ is smaller than 0.5 . The reason for this phenomenon may be that the load of $\mathrm{Fe}_{3} \mathrm{O}_{4}$ increases the specific surface area of the photocatalyst and forms $\mathrm{Fe}-\mathrm{OH}$ on the surface of $\mathrm{Fe}_{3} \mathrm{O}_{4} / \mathrm{BiOBr} /$ BiOI $(x: 3: 1)$ composite, ${ }^{20}$ but the adsorption capacity of $\mathrm{Fe}_{3} \mathrm{O}_{4}$ itself is very small, too much addition will cover the adsorption site of the photocatalyst. The maximum adsorption capacity of $\mathrm{Fe}_{3} \mathrm{O}_{4} / \mathrm{BiOBr} / \mathrm{BiOI}(0.4: 3: 1)$ is $39.31 \mathrm{mg} \mathrm{g}^{-1}$.

Irradiation in visible light for 80 minutes, in the absence of any catalyst, $\mathrm{RhB}$ is difficult to decompose and exhibits excellent chemical stability, which indicates that the direct photolysis is neglectable. In addition, the photodegradation efficiency
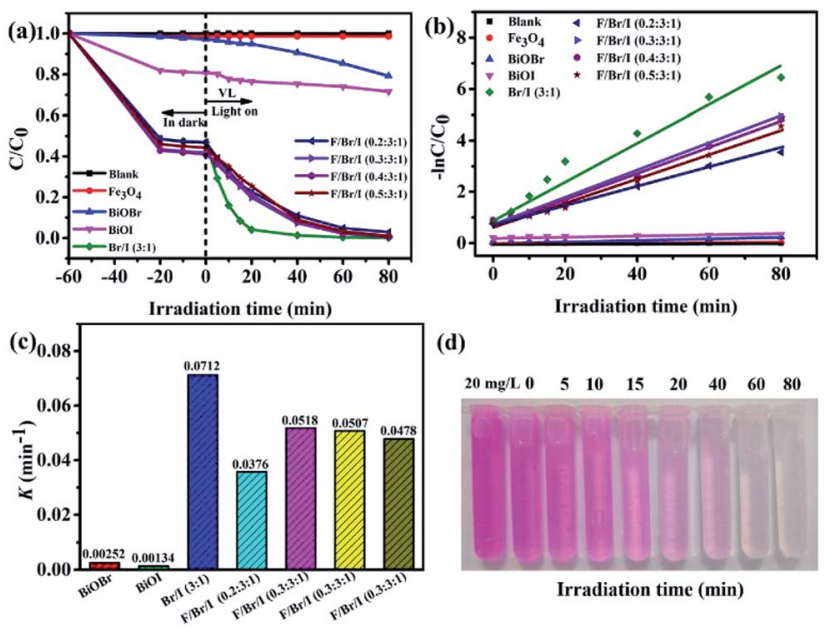

(d)

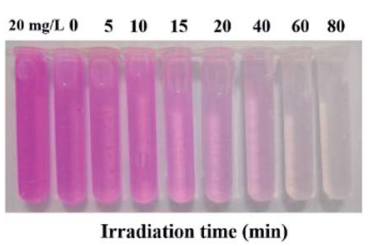

Fig. 8 (a) Photodegradation of RhB over different samples under visible light; (b) the kinetic curves transform of RhB degradation over different samples; (c) first-order kinetic constants (K) of RhB degradation over different samples; (d) the colour change of RhB solution with irradiation time (min) over $\mathrm{Fe}_{3} \mathrm{O}_{4} / \mathrm{BiOBr} / \mathrm{BiOl}(0.4: 3: 1)(\mathrm{Br} /$ I : $\mathrm{BiOBr} / \mathrm{BiOl}(3: 1) ; \mathrm{F} / \mathrm{Br} / \mathrm{l}: \mathrm{Fe}_{3} \mathrm{O}_{4} / \mathrm{BiOBr} / \mathrm{BiOl}$ ).
Table 3 The adsorption capacity of RhB under the prepared samples

\begin{tabular}{lcll}
\hline Samples & $q_{\mathrm{e}}\left(\mathrm{mg} \mathrm{g}^{-1}\right)$ & Samples & $q_{\mathrm{e}}\left(\mathrm{mg} \mathrm{g}^{-1}\right)$ \\
\hline $\mathrm{Fe}_{3} \mathrm{O}_{4}$ & 0.87 & $\mathrm{~F} / \mathrm{Br} / \mathrm{I}^{b}(0.2: 3: 1)$ & 35.45 \\
$\mathrm{BiOBr}$ & 1.86 & $\mathrm{~F} / \mathrm{Br} / \mathrm{I}(0.3: 3: 1)$ & 38.72 \\
$\mathrm{BiOI}$ & 12.79 & $\mathrm{~F} / \mathrm{Br} / \mathrm{I}(0.4: 3: 1)$ & 39.31 \\
$\mathrm{Br} / \mathrm{I}^{a}(3: 1)$ & 35.42 & $\mathrm{~F} / \mathrm{Br} / \mathrm{I}(0.5: 3: 1)$ & 37.14 \\
${ }^{a} \mathrm{BiOBr} / \mathrm{BiOI}$. & \\
& & & \\
& & &
\end{tabular}

of $\mathrm{RhB}$ under the pure $\mathrm{Fe}_{3} \mathrm{O}_{4}$ can be also almost negligible. In the case of pure $\mathrm{BiOBr}$ and $\mathrm{BiOI}, \mathrm{RhB}$ is obviously degraded. And the photodegradation rates of $\mathrm{BiOBr}$ and $\mathrm{BiOI}$ are $20.8 \%$ and $29.4 \%$, respectively. While the corresponding $K$ values are only 0.00252 and $0.00134 \mathrm{~min}^{-1}$. The low degradation rate of BiOI seems to be contrary to PL results, which may be due to the low photogenerated electron-holes produced by BiOI itself. This has a lot to do with the small specific surface area and the agglomerated morphology. It is worth mentioning that the photocatalytic activity of the $\mathrm{BiOBr} / \mathrm{BiOI}(3: 1)$ composite is dramatically enhanced when the BiOBr and BiOI combine with the mole ratio of $3: 1$, and the degradation rate and $K$ of $\mathrm{RhB}$ reach to $99.8 \%$ and $0.0712 \mathrm{~min}^{-1}$, severally, which is attributed to its uniform flower-like hierarchical microsphere structure, larger specific surface area and smaller electron-holes recombination rate. After combined $\mathrm{Fe}_{3} \mathrm{O}_{4}$ with $\mathrm{BiOBr} / \mathrm{BiOI}(3: 1)$, the photocatalytic activities of $\mathrm{Fe}_{3} \mathrm{O}_{4} / \mathrm{BiOBr} / \mathrm{BiOI}(x: 3: 1)(x=0.2$, $0.3,0.4$ and 0.5 ) decrease slightly, and the degradation rates of RhB are 97.1, 99.3, 99.2 and $98.9 \%$, and $K$ values are 0.0376 , $0.0518,0.0507$ and $0.0478 \mathrm{~min}^{-1}$, severally. This result seems to be contrary to the wide absorption band edge and the low photogenerated carrier recombination rate of $\mathrm{Fe}_{3} \mathrm{O}_{4} / \mathrm{BiOBr} / \mathrm{BiOI}$ $(x: 3: 1)(x=0.2,0.3,0.4$ and 0.5$)$. The reason for this result is that the pure $\mathrm{Fe}_{3} \mathrm{O}_{4}$ has no photocatalytic activity on $\mathrm{RhB}$, and the presence of $\mathrm{Fe}_{3} \mathrm{O}_{4}$ covers part of the active sites. To sum up, the inhibitory effect of $\mathrm{Fe}_{3} \mathrm{O}_{4}$ on photocatalytic degradation is stronger than the promoting effect. Data analysis shows that the load of $\mathrm{Fe}_{3} \mathrm{O}_{4}$ improves the adsorption capacity of the photocatalyst, but slightly inhibits the photocatalytic activity.

The color change of RhB solution with irradiation time (min) over $\mathrm{Fe}_{3} \mathrm{O}_{4} / \mathrm{BiOBr} / \mathrm{BiOI}(0.4: 3: 1)$ under visible light is shown in Fig. $8 \mathrm{~d}$. It is evident that the color of RhB solution becomes lighter with the increase of illumination time, until becomes colorless. The colorless RhB solution was detected to confirm the generation of $\mathrm{NH}_{4}{ }^{+}-\mathrm{N}, \mathrm{NO}_{2}{ }^{-}-\mathrm{N}$ or $\mathrm{NO}_{3}{ }^{-}-\mathrm{N}$ by SP-752 visible spectrophotometer. The test result exhibits the existence of $\mathrm{NH}_{4}{ }^{+}$and $\mathrm{NO}_{3}{ }^{-}$, and no $\mathrm{NO}_{2}{ }^{-}$was detected. It is noteworthy that the detected concentrations of $\mathrm{NH}_{4}{ }^{+}-\mathrm{N}$ and $\mathrm{NO}_{3}{ }^{-}-\mathrm{N}$ are $0.74 \mathrm{mg} \mathrm{L}^{-1}$ and $0.46 \mathrm{mg} \mathrm{L}^{-1}$, respectively. The total concentration of $\mathrm{N}$ atoms in $\mathrm{NH}_{4}^{+}$and $\mathrm{NO}_{3}{ }^{-}$is $1.20 \mathrm{mg} \mathrm{L}^{-1}$. The concentration value is basically the same as the concentration of $\mathrm{N}$ atoms $\left(1.26 \mathrm{mg} \mathrm{L}^{-1}\right)$ in RhB solution $\left(20 \mathrm{mg} \mathrm{L}^{-1}\right)$, inferring that nitrogen atoms of RhB in the solution is almost completely degraded.

Reusability of the $\mathrm{Fe}_{3} \mathrm{O}_{4} / \mathrm{BiOBr} / \mathrm{BiOI}(0.4: 3: 1)$ composite. The reusability of the catalyst is also an important index to 
measure the performance of the catalyst. As shown in Fig. 9a, after eight recycles of photocatalytic degradation of RhB over the ternary magnetic $\mathrm{Fe}_{3} \mathrm{O}_{4} / \mathrm{BiOBr} / \mathrm{BiOI}(0.4: 3: 1)$ composite, the degradation rate decreases slightly, from $99.2 \%$ to $82.3 \%$. The magnetic change of the $\mathrm{Fe}_{3} \mathrm{O}_{4} / \mathrm{BiOBr} / \mathrm{BiOI}(0.4: 3: 1)$ catalyst before and after recycling is presented in Fig. 9a (inset), the saturation magnetization decreases from 5.10 to $4.54 \mathrm{emu}^{-1}$, the decrease is only $11 \%$ before and after recycling. The changes of crystalline phase and morphology of the catalysts before and after reaction were observed by XRD and SEM. Seen from Fig. 9b, the $\mathrm{Fe}_{3} \mathrm{O}_{4} / \mathrm{BiOBr} / \mathrm{BiOI}(0.4: 3: 1)$ catalyst maintains good crystallinity before and after reaction, and its morphology do not change significantly. The above analysis results illustrate that the ternary magnetic $\mathrm{Fe}_{3} \mathrm{O}_{4} / \mathrm{BiOBr} / \mathrm{BiOI}(0.4: 3: 1)$ composite has good reusability and stability.

Comparation with previous work. The quality of the catalyst can be reflected when compared with other catalysts. In our previous work, the binary magnetic $\mathrm{Fe}_{3} \mathrm{O}_{4} / \mathrm{BiOBr}(0.5: 1)$ photocatalyst $^{25}$ with better performance than other literatures ${ }^{34-36}$ has been developed. Compared with literature ${ }^{24}$ (Table 4), although the saturation magnetization of $\mathrm{Fe}_{3} \mathrm{O}_{4} / \mathrm{BiOBr} / \mathrm{BiOI}$ $(0.4: 3: 1)$ is smaller than that of $\mathrm{Fe}_{3} \mathrm{O}_{4} / \mathrm{BiOBr}(0.5: 1)$, the specific surface area, adsorption capacity, degradation activity and $K$ value are larger than those of binary magnetic $\mathrm{Fe}_{3} \mathrm{O}_{4}$ / $\operatorname{BiOBr}(0.5: 1)$ photocatalyst. Previous study ${ }^{24}$ has also synthesized ternary magnetic $\mathrm{Fe}_{3} \mathrm{O}_{4} / \mathrm{BiOBr} / \mathrm{BiOI}(0.5: 2: 2)$ composite by precipitation method. As presented in Table 4 , the saturation magnetization of $\mathrm{Fe}_{3} \mathrm{O}_{4} / \mathrm{BiOBr} / \mathrm{BiOI}(0.4: 3: 1)$ is slightly smaller than that of $\mathrm{Fe}_{3} \mathrm{O}_{4} / \mathrm{BiOBr} / \mathrm{BiOI}(0.5: 2: 2)$, but $\mathrm{Fe}_{3} \mathrm{O}_{4}$ / $\mathrm{BiOBr} / \mathrm{BiOI}(0.4: 3: 1)$ can also be well separated from water under magnetic field within $25 \mathrm{~s}$. Besides, the specific surface area of $\mathrm{Fe}_{3} \mathrm{O}_{4} / \mathrm{BiOBr} / \mathrm{BiOI}(0.5: 2: 2)\left(28.21 \mathrm{~m}^{2} \mathrm{~g}^{-1}\right)$ is much less than that of $\mathrm{Fe}_{3} \mathrm{O}_{4} / \mathrm{BiOBr} / \mathrm{BiOI}(0.4: 3: 1)\left(48.30 \mathrm{~m}^{2} \mathrm{~g}^{-1}\right)$. The specific surface area of this paper is 3 times that of literature, ${ }^{24}$ which may indicate higher adsorption capacity and degradation activity of $\mathrm{Fe}_{3} \mathrm{O}_{4} / \mathrm{BiOBr} / \mathrm{BiOI}(0.4: 3: 1)$.

\section{Mechanism of photocatalytic activity}

The band gap energy $\left(E_{\mathrm{g}}\right)$ of the semiconductor can be evaluated by the following calculation formula:

$$
E_{\mathrm{g}}=h c / \lambda_{0}=1240 / \lambda_{0}
$$
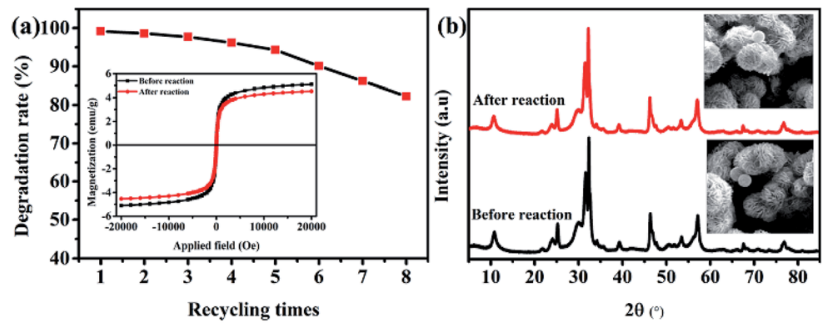

Fig. 9 (a) Recycling utilization experiments and magnetism of $\mathrm{Fe}_{3} \mathrm{O}_{4} /$ $\mathrm{BiOBr} / \mathrm{BiOl}(0.4: 3: 1)$ composite before and after recycling (inset); (b) XRD patterns and SEM images (inset) of $\mathrm{Fe}_{3} \mathrm{O}_{4} / \mathrm{BiOBr} / \mathrm{BiOI}(0.4: 3: 1)$ composite before and after recycling. where $c, h, \lambda_{0}$ are the velocity of light, Planck constant and the maximum absorption wavelength, respectively. The $E_{\mathrm{g}}$ of $\mathrm{BiOBr}$ and $\mathrm{BiOI}$ are calculated to be 2.92 and $1.85 \mathrm{eV}$, which is consistent with the literature report. ${ }^{27,37}$ The valence band (VB) edge position and the conduction band (CB) edge position of $\mathrm{BiOBr}$ and BiOI can be calculated by Mulliken electronegativity theory via formulas (3) and (4):

$$
\begin{gathered}
E_{\mathrm{CB}}=X-E_{\mathrm{c}}-0.5 E_{\mathrm{g}} \\
E_{\mathrm{VB}}=E_{\mathrm{g}}+E_{\mathrm{CB}}
\end{gathered}
$$

here $E_{\mathrm{c}}$ is the energy of free electrons on the hydrogen scale, about $4.5 \mathrm{eV}$. And $X$ is the absolute electronegativity of the samples. The $X$ values of $\mathrm{BiOBr}$ and $\mathrm{BiOI}$ are 6.21 and $6.45 \mathrm{eV}$. According to the formulas (3) and (4), the $E_{\mathrm{CB}}$ and $E_{\mathrm{VB}}$ of BiOI are 0.78 and $2.63 \mathrm{eV}$, respectively, and those of $\mathrm{BiOBr}$ are 0.49 and $3.42 \mathrm{eV}$. The band edge potentials of the $\mathrm{VB}$ and $\mathrm{CB}$ of $\mathrm{BiOBr}$ and BiOI are presented in Fig. 10a.

Under light illumination, since the energy of photons is greater than the difference between LUMO and HOMO of dyes, the transition of electrons $\left(\mathrm{e}^{-}\right)$in dyes molecules occurs to form dyes $^{+}$which can continue to decompose into small molecules. However, the electrons and dyes ${ }^{+}$are very easy to recombine to form dye molecules, which is the reason that the $\mathrm{RhB}$ is almost not degraded in the absence of photocatalyst. In the presence of photocatalysts, the situation will be greatly changed.

In $\mathrm{RhB}$ aqueous solution with $\mathrm{Fe}_{3} \mathrm{O}_{4} / \mathrm{BiOBr} / \mathrm{BiOI}(0.4: 3: 1)$ photocatalyst under visible light illumination $(\lambda>400 \mathrm{~nm}$, energy less than $3.10 \mathrm{eV}$ ), the energy of photons is larger than the $E_{\mathrm{g}}$ of $\mathrm{BiOI}(1.85 \mathrm{eV})$ and $\mathrm{BiOBr}(2.92 \mathrm{eV})$, the $\mathrm{e}^{-}$on the $\mathrm{VB}$ of $\mathrm{BiOI}(2.63 \mathrm{eV})$ and $\mathrm{BiOBr}(3.42 \mathrm{eV})$ transmits to the $\mathrm{CB}$ of BiOI $(0.78 \mathrm{eV})$ and $\mathrm{BiOBr}(0.49 \mathrm{eV})$, so this will produce photoelectron-hole pairs $\left(\mathrm{e}^{-}-\mathrm{h}^{+}\right)$(reaction (5)). As shown in Fig. 10a, the $\mathrm{CB}$ edge potentials of $\mathrm{BiOI}(0.78 \mathrm{eV})$ and $\mathrm{BiOBr}(0.49 \mathrm{eV})$ seem to be detrimental to the transmission of electrons. In fact, it can be seen from the Fig. 10b, the electrons on the VB of BiOI $(2.63 \mathrm{eV})$ and $\mathrm{BiOBr}(3.42 \mathrm{eV})$ can be stimulated to the more negative potentials (BiOI of $-0.47 \mathrm{eV}$, and $\mathrm{BiOBr}$ of $0.32 \mathrm{eV}$ ). At this point, the $\mathrm{CB}$ of $\mathrm{BiOBr}(0.32 \mathrm{eV})$ is more positive potential than that of $\mathrm{BiOI}(-0.47 \mathrm{eV})$, which makes it possible for electrons to transfer from the $\mathrm{CB}$ of $\mathrm{BiOI}$ to the $\mathrm{CB}$ of BiOBr. Absorbed photons (energy less than $3.10 \mathrm{eV}$ ) with greater energy than the difference between LUMO $(-1.42 \mathrm{eV})$ and HOMO $(0.95 \mathrm{eV})$ of $\mathrm{RhB}$, the electrons of $\mathrm{RhB}$ are excited to produce $\mathrm{RhB}^{+}$(reaction (6)), and actively migrate to the $\mathrm{CB}$ position of BiOI due to the more negative potential of LUMO $(-1.42 \mathrm{eV})$ than the $\mathrm{CB}$ potential of BiOI $(-0.47 \mathrm{eV})$. And $\mathrm{RhB}^{+}$can decompose into small molecules or $\mathrm{CO}_{2}, \mathrm{H}_{2} \mathrm{O}, \mathrm{NO}_{3}{ }^{-}$and $\mathrm{NH}_{4}{ }^{+}$(reaction (7)). At the same time, the $\mathrm{h}^{+}$on the $\mathrm{VB}$ of $\mathrm{BiOBr}$ automatically transfers to the $\mathrm{VB}$ of $\mathrm{BiOI}$ because of the more positive VB potential of $\mathrm{BiOBr}(3.42 \mathrm{eV})$ than that of BiOI $(2.63 \mathrm{eV})$. Through the above principle analysis, the flow of electron-hole pairs establishes an external circuit to form a virtuous cycle, which promotes the continuation of photocatalytic process.

Next comes the production of active free radicals. The holes on the $\mathrm{VB}$ of $\mathrm{BiOI}$ will react with $\mathrm{H}_{2} \mathrm{O}$ molecules to emerge $\cdot \mathrm{OH}$ 
Table 4 Compare this paper with $\mathrm{Fe}_{3} \mathrm{O}_{4} / \mathrm{BiOBr}(0.5: 1)$ in our previous work ${ }^{25}$ and literature ${ }^{24 a}$

\begin{tabular}{|c|c|c|c|c|c|}
\hline Magnetic photocatalyst & $\begin{array}{l}M \\
\left(\mathrm{emu} \mathrm{g}^{-1}\right)\end{array}$ & $S\left(\mathrm{~m}^{2} \mathrm{~g}^{-1}\right)$ & $q_{\mathrm{e}}\left(\mathrm{mg} \mathrm{g}^{-1}\right)$ & $D(\%)$ & $K\left(\min ^{-1}\right)$ \\
\hline 25 & 17.3 & 34.11 & 14.53 & 78.4 & 0.035 \\
\hline This paper & 5.1 & 48.30 & 39.31 & 99.2 & 0.0507 \\
\hline
\end{tabular}

${ }^{a} M$ : magnetization; $S$ : specific surface area; $D$ : degradation activity.

(reaction (8)), which is due to the more positive potential VB of BiOI than the redox potential of $\mathrm{OH}^{-} / \cdot \mathrm{OH}(1.99 \mathrm{eV}) \cdot{ }^{38}$ While $\mathrm{e}^{-}$ can be delivered by the $\mathrm{Fe}_{3} \mathrm{O}_{4}$ particles with strong electron transfer ability (reaction (9)). Because the $\mathrm{CB}$ potential of BiOI $(-0.47 \mathrm{eV})$ is more negative than the potential of $\mathrm{O}_{2} / \cdot \mathrm{O}_{2}{ }^{-}$ $(-0.046 \mathrm{eV}){ }^{39}$ the electrons transferred by $\mathrm{Fe}_{3} \mathrm{O}_{4}$ particles combine with $\mathrm{O}_{2}$ molecules to form $\cdot \mathrm{O}_{2}{ }^{-}$(reaction (10)), and subsequently produce $\mathrm{H}_{2} \mathrm{O}_{2}\left(\mathrm{O}_{2} / \mathrm{H}_{2} \mathrm{O}_{2}, 0.682 \mathrm{eV}\right.$ ) (reaction (11)), which can reaction with $\mathrm{e}^{-}$to emerge $\cdot \mathrm{OH}$ and $\mathrm{OH}^{-}$(reaction (12)). ${ }^{40} \cdot \mathrm{OH}, \cdot \mathrm{O}_{2}{ }^{-}$and $\mathrm{H}_{2} \mathrm{O}_{2}$ are oxidants, which can oxidize $\mathrm{RhB}$ molecules and $\mathrm{RhB}^{+}$into small molecules, until RhB molecules and $\mathrm{RhB}^{+}$are oxidized into $\mathrm{CO}_{2}, \mathrm{H}_{2} \mathrm{O}, \mathrm{NH}_{4}{ }^{+}$and $\mathrm{NO}_{3}{ }^{-}$(reaction (13)). The possible photocatalytic reactions of the ternary magnetic $\mathrm{Fe}_{3} \mathrm{O}_{4} / \mathrm{BiOBr} / \mathrm{BiOI}(0.4: 3: 1)$ photocatalyst are as follows:

$$
\begin{gathered}
\mathrm{BiOBr} / \mathrm{BiOI}+h \nu \rightarrow \mathrm{BiOBr} / \mathrm{BiOI}\left(\mathrm{h}^{+}+\mathrm{e}^{-}\right) \\
\mathrm{RhB}+h \nu \rightarrow \mathrm{RhB}^{+}+\mathrm{e}^{-} \\
\mathrm{RhB}^{+} \rightarrow \text { intermediates }+\mathrm{CO}_{2}+\mathrm{H}_{2} \mathrm{O}+\mathrm{NO}_{3}{ }^{-}+\mathrm{NH}_{4}^{+} \\
\mathrm{H}_{2} \mathrm{O}+\mathrm{BiOBr} / \mathrm{BiOI}\left(\mathrm{h}^{+}\right) \rightarrow \mathrm{BiOBr} / \mathrm{BiOI}+\mathrm{H}^{+}+\cdot \mathrm{OH} \\
\mathrm{BiOBr} / \mathrm{BiOI}\left(\mathrm{e}^{-}\right)+\mathrm{Fe}_{3} \mathrm{O}_{4} \rightarrow \mathrm{BiOBr}^{+} \mathrm{BiOI}+\mathrm{Fe}_{3} \mathrm{O}_{4}\left(\mathrm{e}^{-}\right) \\
\mathrm{Fe}_{3} \mathrm{O}_{4}\left(\mathrm{e}^{-}\right)+\mathrm{O}_{2} \rightarrow \mathrm{Fe}_{3} \mathrm{O}_{4}+\cdot \mathrm{O}_{2}{ }^{-} \\
2 \cdot \mathrm{O}_{2}^{-}+2 \mathrm{H}^{+} \rightarrow \mathrm{O}_{2}+\mathrm{H}_{2} \mathrm{O}_{2} \\
\mathrm{H}_{2} \mathrm{O}_{2}+\mathrm{Fe}_{3} \mathrm{O}_{4}\left(\mathrm{e}^{-}\right) \rightarrow \cdot \mathrm{OH}+\mathrm{OH}^{-}+\mathrm{Fe}_{3} \mathrm{O}_{4}
\end{gathered}
$$

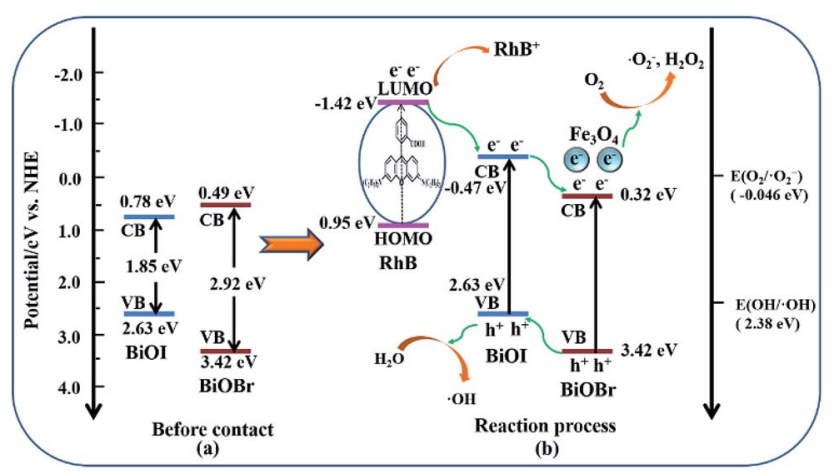

Fig. 10 The photodegradation mechanism for $\mathrm{RhB}$ over $\mathrm{Fe}_{3} \mathrm{O}_{4} / \mathrm{BiOBr} /$ $\mathrm{BiOl}(0.4: 3: 1)$ under visible-light irradiation $(\lambda>400 \mathrm{~nm}$, central optical power with $250 \mathrm{~mW} \mathrm{~cm}^{-2}$ ).

$$
\begin{aligned}
\mathrm{RhB} \text { and } \mathrm{RhB}^{+} & +\cdot \mathrm{OH}, \cdot \mathrm{O}_{2}^{-} \text {and } \mathrm{H}_{2} \mathrm{O}_{2} \\
& \rightarrow \mathrm{CO}_{2}+\mathrm{H}_{2} \mathrm{O}+\mathrm{NO}_{3}{ }^{-}+\mathrm{NH}_{4}{ }^{+}
\end{aligned}
$$

\section{Conclusions}

The ternary magnetic $\mathrm{Fe}_{3} \mathrm{O}_{4} / \mathrm{BiOBr} / \mathrm{BiOI}(x: 3: 1)$ composites were synthesized by a facile solvothermal method. The cha ' $r$ acterization results reveal that all the $\mathrm{Fe}_{3} \mathrm{O}_{4} / \mathrm{BiOBr} / \mathrm{BiOI}$ $(x: 3: 1)$ samples possess good visible light response and large specific surface area. The $\mathrm{RhB}\left(20 \mathrm{mg} \mathrm{L}^{-1}\right)$ solution can be degraded to colorless within $80 \mathrm{~min}$ over $\mathrm{Fe}_{3} \mathrm{O}_{4} / \mathrm{BiOBr} / \mathrm{BiOI}$ (0.4:3:1) photocatalyst. $\mathrm{Fe}_{3} \mathrm{O}_{4} / \mathrm{BiOBr} / \mathrm{BiOI}(0.4: 3: 1)$ can be rapidly separated from water within $25 \mathrm{~s}$ under external magnetic field. After 8 times recycles, the degradation rate decreases slightly, from $99.2 \%$ to $82.3 \%$, the saturation magnetization decreases only $11 \%$, and the crystallinity and morphology have not changed. Compared with binary magnetic $\mathrm{Fe}_{3} \mathrm{O}_{4} / \mathrm{BiOBr}(0.5: 1)$ prepared by the same method in our previous work and the previous $\mathrm{Fe}_{3} \mathrm{O}_{4} / \mathrm{BiOBr} / \mathrm{BiOI}(0.5: 2: 2)$ synthesized by co-precipitation method, the photocatalytic activity and adsorption capacity of $\mathrm{Fe}_{3} \mathrm{O}_{4} / \mathrm{BiOBr} / \mathrm{BiOI}(0.4: 3: 1)$ are superior to them. All the results show the high photocatalytic degradation efficiency, good magnetic separation performance and excellent recyclability and stability of ternary magnetic $\mathrm{Fe}_{3} \mathrm{O}_{4} / \mathrm{BiOBr} / \mathrm{BiOI}(0.4: 3: 1)$ photocatalyst. Photocatalytic mechanism analysis presents that RhB is degraded by oxidation of $\cdot \mathrm{OH}, \cdot \mathrm{O}_{2}{ }^{-}$and $\mathrm{H}_{2} \mathrm{O}_{2}$.

\section{Conflicts of interest}

There are no conflicts to declare.

\section{Acknowledgements}

This work has been supported by the National Natural Science Foundation of China (21776196, 51778397 and 21707098), the National Key Research and Development Project (2016YFB0600502) and Innovative Projects for Post-graduate Education of Shanxi Province (No. 2018BY046).

\section{References}

1 H. Sun, S. Liu, G. Zhou, H. Ming Ang, M. O Tadé and S. Wan, ACS Appl. Mater. Interfaces, 2012, 4, 5466-5471. 
2 L. Schaider, K. Rodgers and R. A. Rudel, Environ. Sci. Technol., 2017, 51, 7304-7317.

3 P. Falås, A. Wick, S. Castronovo, J. Habermacher, T. Ternes and A. Joss, Water Res., 2016, 95, 240-249.

4 S. Sun and W. Wang, RSC Adv., 2014, 4, 47136-47152.

5 M. Cao, P. Wang, Y. Ao, C. Wang, J. Hou and J. Qian, Chem. Eng. J., 2015, 264, 113-124.

6 L. Reddy, J. Arias, J. Nicolas and P. Couvreur, Chem. Rev., 2012, 112, 5818-5878.

7 D. Sudha and P. Sivakumar, Chem. Eng. Process., 2015, 97, 112-133.

8 T. Xiong, M. Wen, F. Dong, J. Yu, L. Han, B. Lei, Y. Zhang, X. Tang and Z. Zang, Appl. Catal., B, 2016, 199, 87-95.

9 J. Joo, M. Dahl, N. Li, F. Zaera and Y. Yin, Energy Environ. Sci., 2013, 6, 2082-2092.

10 S. Hoang, S. Guo, N. T. Hahn, A. J. Bard and C. Buddie Mullins, Nano Lett., 2012, 12, 26-32.

11 G. Liao, Y. Gong, L. Zhang, H. Gao, G. Yang and B. Fang, Energy Environ. Sci., 2019, 12, 2080-2147.

12 A. Ajmal, I. Majeed, R. Malik, H. Idriss and M. Nadeem, RSC Adv., 2014, 4, 37003-37026.

13 Y. Hu, W. Chen, J. Fu, M. Ba, F. Sun, P. Zhang and J. Zou, Appl. Surf. Sci., 2018, 436, 319-326.

14 Y. Wang, Y. Long, Z. Yang and D. Zhang, J. Hazard. Mater., 2018, 351, 11-19.

15 P. Zhang, B. Y. Guan, L. Yu and X. W. Lou, Chem, 2018, 4, 162-173.

16 J. Li, M. Han, Y. Guo, F. Wang, L. Meng, D. Mao, S. Ding and C. Sun, Appl. Catal., A, 2016, 524, 105-114.

17 W. Deng, S. Ci, H. Li and Z. Wen, Chem. Eng. J., 2017, 330, 995-1001.

18 T. Wang, L. Zhang, H. Wang, W. Yang, Y. Fu, W. Zhou, W. Yu, K. Xiang, Z. Su, S. Dai and L. Chai, ACS Appl. Mater. Interfaces, 2013, 5, 12449-12459.

19 J. Liang, F. Liu, M. Li, W. Liu and M. Tong, Water Res., 2018, 137, 120-129.

20 D. Wang, J. Li, Z. Xu, Y. Zhu and G. Chen, J. Colloid Interface Sci., 2019, 533, 344-357.

21 M. Shekofteh-Gohari and A. Habibi-Yangjeh, Ceram. Int., 2015, 41, 1467-1476.
22 M. Mousavi, A. Habibi-Yangjeh and D. Seifzadeh, J. Mater. Sci. Technol., 2018, 34, 1638-1651.

23 N. Güy, K. Atacan, E. Karaca and M. Özacar, Sol. Energy, 2018, 166, 308-316.

24 S. Gao, C. Guo, S. Hou, L. Wan, Q. Wang, J. Lv, Y. Zhang, J. Gao, W. Meng and J. Xu, J. Hazard. Mater., 2017, 331, 1-12.

25 J. Li, F. Yang, Q. Zhou, R. Ren, L. Wu and Y. Lv, J. Colloid Interface Sci., 2019, 546, 139-151.

26 J. Fu, B. Chang, Y. Tian, F. Xi and X. Dong, J. Mater. Chem. A, 2013, 1, 3083-3090.

27 W. An, W. Cui, Y. Liang, J. Hu and L. Liu, Appl. Surf. Sci., 2015, 351, 1131-1139.

28 Y. Huo, J. Zhang, M. Miao and Y. Jin, Appl. Catal., B, 2012, 111-112, 334-341.

29 X. Wu, R. Wang, Y. Du, X. Li, H. Meng and X. Xie, New J. Chem., 2019, 43, 2640-2648.

30 L. Lin, M. Huang, L. Long, Z. Sun, W. Zheng and D. Chen, Ceram. Int., 2014, 40, 11493-11501.

31 Z. Liu, H. Ran, B. Wu, P. Feng and Y. Zhu, Colloids Surf., A, 2014, 452, 109-114.

32 S. Gao, C. Guo, J. Lv, Q. Wang, Y. Zhang, S. Hou, J. Gao and J. Xu, Chem. Eng. J., 2017, 307, 1055-1065.

33 M. Shekofteh-Gohari and A. Habibi-Yangjeh, J. Colloid Interface Sci., 2016, 461, 144-153.

34 C. Guo, Y. He, P. Du, X. Zhao, J. Lv, W. Meng, Y. Zhang and J. Xu, Appl. Surf. Sci., 2014, 320, 383-390.

35 G. Cao, G. Wang, Y. Bai and M. Liu, Micro Nano Lett., 2015, 10, 115-118.

36 C. Guo, S. Gao, J. Lv, S. Hou, Y. Zhang and J. Xua, Appl. Catal., $B, 2017,205,68-77$.

37 H. Huang, K. Xiao, Y. He, T. Zhang, F. Dong, X. Du and Y. Zhang, Appl. Catal., B, 2016, 199, 75-86.

38 L. Yosefi, M. Haghighi and S. Allahyari, Sep. Purif. Technol., 2017, 178, 18-28.

39 J. Hou, K. Jiang, M. Shen, R. Wei, X. Wu, F. Idrees and C. Cao, Sci. Rep., 2017, 7, 11665.

40 N. Lu, Y. Wang, S. Ning, W. Zhao, M. Qian, Y. Ma, J. Wang, L. Fan, J. Guan and X. Yuan, Sci. Rep., 2017, 7, 17298. 